\title{
Managing Competition for Nutrients in Agro-Ecosystems
}

\author{
Moses Imo \\ Department of Forestry and Wood Science, \\ Chepkoilel University College, Moi University, Eldoret, \\ Kenya
}

\section{Introduction}

Knowledge of competitive plant interactions is important in designing more productive cropping systems in both agriculture and forestry. These interactions are often variable in nature, and may be competitive, synergistic or complementary depending on several factors such as species mixture, environmental conditions and management practices, which are also influenced by prevailing socioeconomic factors. Most of these interactions often involve primarily competition for the major plant growth resources namely: light, moisture, nutrients and space. Unfortunately, segregating the specific mechanisms involved at any time in the competition process has often been a major problem for many agro-ecologists because of the complex interactive nature of the requirements by plants for these growth resources. Although significant attempts and gains have been made with respect to understanding mechanisms for competition for a single aboveground resource (i.e. light), little progress has been made with respect to competition for a broad range of belowground resources (i.e. nutrients and moisture). This is mainly because of the multiple belowground interactions involving complex processes and mechanisms of availability, uptake and utilization by plants. In the case of nutrients, plants compete for a broad range of essential plant mineral elements that differ in molecular size, valence, oxidation state and mobility within the soil. Unofortunately, and leess understood, belowground competition often reduces plant performance more than aboveground competition (Wilson 1988), and it is the principal form of competition occurring in ecosystems with extremely low plant densities such as arid lands and low fertility sites (Fowler, 1986).

This chapter reviews the mechanisms and ecological importance of nutrient competition, emphasizing methodologies for measuring nutrient compeition in cropping systems and their advantages and limitations. This is particularly important in understanding the roles of plant competition for nutrients in the productivity of agro-ecosystems, and provide guidelines for their management. The approach is to combine knowledge in soil fertility and plant nutrition with physiological ecology in order to merge various diagnostic tools for decision making at farm level. The goal is to illustrate a simple graphical diagnostic model for identifying overall nutrient interaction effects and how to optimize various factors affecting nutrient competition in different agro-ecosystems. To be useful, such tools must help determine the benefits and consequences of crop and weed management strategies in any give system, and facilitate determination of the relative importance of various interaction types and the associated specific mechanisms. 


\section{Definition and importance of nutrient competition}

Competition for soil nutrients is one of the major factors that structure plant communities (Grace and Tilman 1990). Understanding the mechanisms that control plant competition for soil nutrients is therefore an essential step in predicting the outcome of interspecific competition in many plant communities, and in designing effective cultural practices in agro-ecosystems. Generally, plant competition is broadly defined as the process by which two or more individual plants or populations of plants interact, such that at least one exerts a negative effect on its neighbor in terms of reduced survivorship, growth or reproduction. Competition for nutrients therefore can be said to occur when a plant depletes a soil nutrient and negatively impacts availability of the nutrient element to which another plant shows a positive response. This definition, which is derived from that of Goldberg (1990), essentially means that the reduced level of the nutrient (an intermediary resource), has a negative effect on the performance of the competing plants measured per individual or per unit size. The advantage of this physiologically based definition identifies how nutrient uptake by one individual plant can affect the quantity of the nutrient taken up by another, and often help determine the consequences for plant performance as shown in Figure 1.

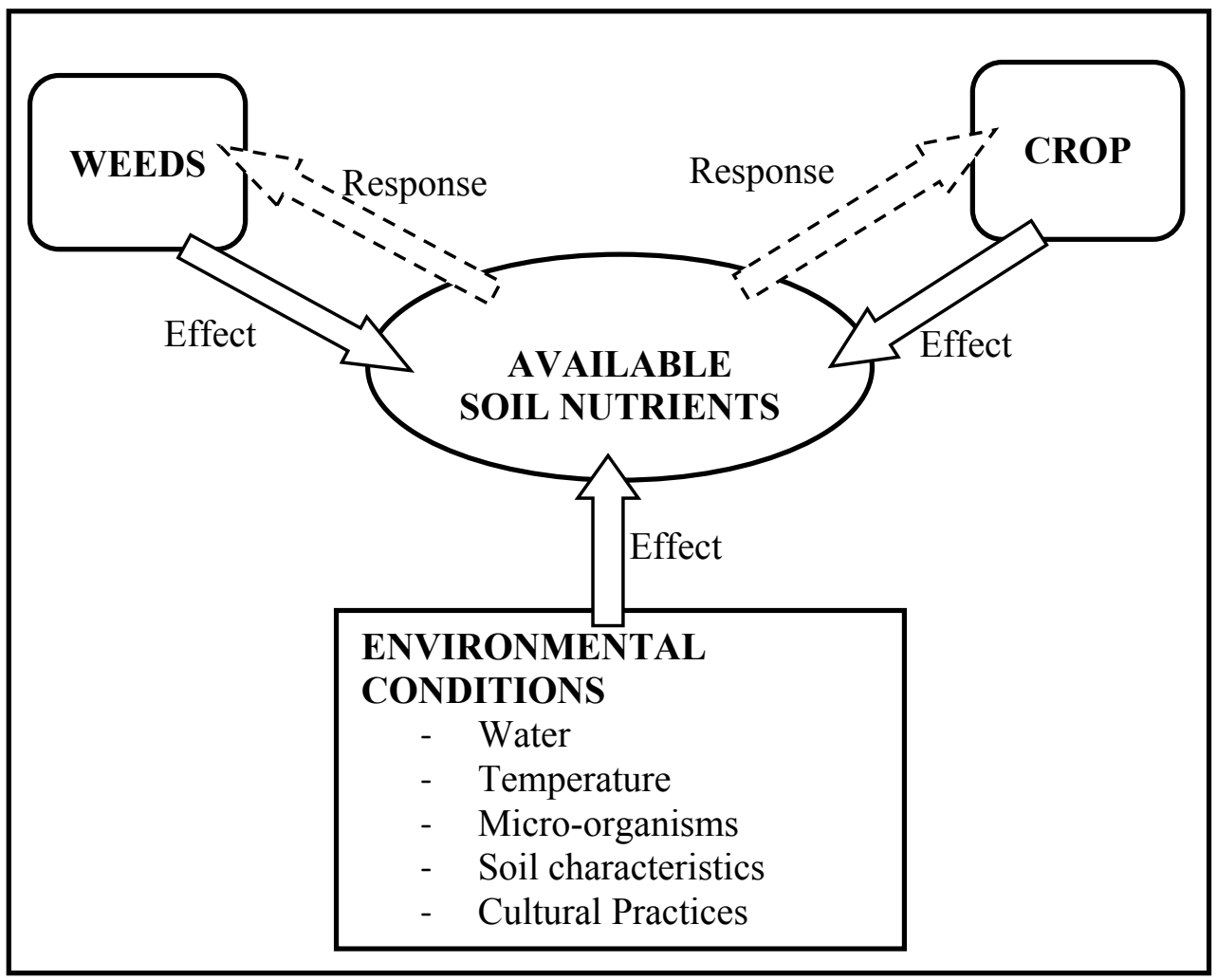

Fig. 1. Plant competition for nutrients showing the effects and responses of competing plants to changing nutrient availability. Both the effect and the response should have the appropriate sign for competition to occur. 
Characteristically, like competition for all the other growth resources, nutrient competition is reciprocal, i.e., it occurs only when nutrient resources are in limited supply. The competing plants can either be of the same species (intraspecific competition) or of different species (interspecific competition). These responses are usually described by yield-density relationships that follow the 'law of constant final yield' (Begon et al. 1996). That is, at low density, total resource availability to each individual plant is high resulting in a few large individuals, and total growth will respond to small changes in density. At high densities, however, resource availability to each individual is low resulting in many small individuals, and total production is less responsive to changes in density and attains a final constant value reflecting complete utilization of available growth resources. When one species has a negative effect on the second species, yet both can utilize more efficiently available resources when in mixture than in monoculture, it is referred to as the interference, but it is facilitation if one species has a positive effect on the other (Vandermeer, 1984). The term interaction is also often used to simply mean mutual or reciprocal effects in situations where species performance in mixtures is not equal to the sum of their performances when they are grown separately. Although plant interactions may also be due to other effects such as allelopathy through production of toxins, parasitism by natural enemies and mutualisms, the focus in this chapter, however, is on interactions involving soil nutrients.

\section{Mechanisms of plant competition for nutrients}

\subsection{Nutrient uptake}

Soil nutrients reach the root surfaces for uptake through three general processes (Marschner, 1995): root interception (the capture of nutrients as the root grows through the soil, physically displacing soil particles and clay surfaces), mass flow (the movement of dissolved mineral nutrients in water driven by plant transpiration and is a function of the rate of water movement to the root and the concentration of dissolved nutrients), and diffusion of nutrients toward the root surfaces when nutrient uptake exceeds the supply by mass flow thereby creating localized nutrient concentration gradients. Overall, root interception is the least important of the three processes, while diffusion occurs only when mass flow and root interception are inadequate to meet plant requirements. However, these mechanisms almost always work together. Various mechanisms have been proposed to explain partitioning of soil nutrients among neighboring competing plants, and corresponding theories are often linked to a specific theoretical framework developed for a specific type of ecological system under study. Overall, the competitive ability of a plant is determined by its capacity to capture and exploit resources rapidly and the ability to utilize shared nutrient resources in shortest supply by two or more species (Tilman 1988). Thus, understanding mechanisms of nutrient partitioning requires knowledge of factors related to the plant's ability to acquire a greater proportion of nutrients, utilize nutrients more efficiently, and allocate assimilates in ways that maximize the capacity of an individual for survival and growth (Berendse and Elberse 1990; Nambiar and Sands 1993). These factors are discussed below.

\subsection{Nutrient acquisition strategies by plants}

The characteristics of plant root systems (e.g. root length, density, surface area and diameter), rates of nutrient diffusion in the soil and uptake by plants, morphological and 
physiological plasticity, and spatial and temporal soil partitioning are the major factors determining the nutrient competitive ability of most plant nutrient competition (Gillespie 1989; Neary et al. 1990; Smethurst and Comerford 1993). Generally, these factors have been used to predict nutrient uptake of competing plants as a function of the nutrient concentration in solution at the soil-root interface, which is determined by the balance between plant demand for nutrients and the ability of the soil to supply that demand. As roots absorb nutrients, concentrations around the root surface declines, thus creating 'nutrient depletion zones' around the root surface. Nutrient competition then occurs when the depletion zones for adjacent roots overlap, thus interfering with nutrient availability for each plant and resulting in reduced uptake.

Root morphology plays a major role in determining nutrient depletion. Regardless of nutrient mobility, competition for all nutrients increases with root length or density (Barber 1984; Gillespie 1989). In addition, thicker roots have steeper depletion gradients and wider depletion zones than thinner roots. Hence, thinner and longer roots are less likely to compete than thicker and shorter roots because finer roots will be able to absorb nutrients at much lower nutrient concentration in solution (Sands and Mulligan 1990). Spatial segregation of roots of different species may reduce interspecific competition. For example, the ability of woody plants to develop deep rooting systems (Eastham and Rose 1990; Stone and Kalisz 1991) may be an important strategy to avoid competition with shallow rooted herbaceous plants. However, roots of most woody plants are also concentrated in the surface soil (Nambiar 1990), thus making direct competition with herbaceous plants inevitable.

\subsection{Nutrient use by plants}

Plant growth usually increases with the amount of nutrient present in biomass. However, there are considerable species differences in the amount of nutrients required to produce biomass (Wang et al. 1991), indicating the differential ability in species to utilize nutrients for growth (i.e. nutrient-use-efficiency [NUE]). Generally, trees produce more biomass per unit of nutrients (i.e. higher NUE) than herbaceous weedy species, probably because trees increasingly produce woody tissue which is low in nutrients as it is not active photosynthetic tissue (Chapin 1990; van den Driessche 1991; Nambiar and Fife, 1991). This mechanism partially explains why the capacity of trees to dominate a site accelerates with increasing age of the trees.

Nutrient losses from a plant (litter fall, leaching, root decay and herbivory) also determine the plant's total nutrient requirements, i.e. the amount of nutrient that must be absorbed by an individual or population just to maintain or replace its biomass (Berendse and Elberse 1990). A species with low nutrient loss rate and high uptake rate and/or higher NUE will have a relatively low demand for external nutrients. According to Tilman (1988), such a species is predicted to be able to meet its nutrient requirements at a lower soil nutrient supply rate, and its total biomass will increase only if it absorbs more nutrients than its demand, but declines if it absorbs less. Hence, partitioning of a limiting nutrient between competing species is expected to be proportional to their demand relative to uptake; therefore, a species with a low demand relative to uptake will have a higher competitive ability. 


\subsection{Carbon allocation}

Relative allocation of assimilates to root and shoot growth modifies root-shoot ratios of plants and influences the ability of plants to acquire below- and above-ground resources. Thus, one critical point in understanding plant strategies in overcoming nutrient competition is the allocation of growth to below-ground during nutrient limitations (Chapin 1980). Root-shoot ratios increase with reduced nutrient availability (Axelsson and Axelsson 1986; Boot and Mensink 1990) perhaps as a means of enhancing nutrient acquisition from the soil. However, such data must be analyzed with caution since the positive effects of nutrient status (e.g. higher nutrient concentration in plant tissue) on plant growth can overshadow the effect of preferred growth allocation to roots. For example, high soil nutrient availability may enhance both root and shoot growth resulting in a larger root system, but root-shoot ratio may decline.

\subsection{Nutrient interactions with other resources}

Since plant growth involves acquisition of multiple resources, interactions among these resources in the environment (particularly in the soil) can complicate interpretation of competition effects. As discussed earlier, soil moisture can greatly affect nutrient availability and uptake, while light can alter demand for the nutrients thus influencing the outcome of competition for the nutrients in short supply. Also, removal of one species may increase availability of all resources together because of reduced uptake, or the removal may indirectly modify resource availability through microclimate modification, as has been demonstrated in other weed control experiments (Smesthurst and Nambiar 1989; Woods et al. 1990). In these studies, weed removal by herbicide application increased available moisture and nutrients, and altered soil temperature that favored faster $\mathrm{N}$ mineralization. Weed removal (especially in young plantations) also increases light availability that favors faster growth and further creates a larger demand for soil moisture and nutrients. This evidence demonstrates the need for a systematic and integrated approach to resource competition studies to allow a better segregation of the competition processes involved. Figure 2 is a conceptual model for resource competition by plants that provides a comprehensive starting point for any such approach. Since interspecific interactions may result in either reduced growth (competition) or enhanced productivity (synergism), understanding processes of resource partitioning is necessary to increasing productivity in these ecosystems, and requires knowledge of soil and plant processes related to nutrient availability, uptake and utilization by plants.

\section{Framework for understanding plant competition for nutrients}

\subsection{Ecological relationships}

The model is based on Berkowitz's conceptual model of plant competition for resources (Berkowitz 1988), simplified here to illustrate the key processes involved as shown in Figure 2. This diagram distinguishes three major variables: state, rate and intermediate variables. State variables (represented by boxes in Figure 2) are measurable quantities (biomass, nutrient content, soil water, soil nutrients and solar radiation). Each state variable is characterized by a rate or efficiency variable (represented as valves in Figure 2) that determines the rate of flow in material or energy between state variables due to specific 
processes (represented as hexagons in Figure 2). The intermediate variables (represented as circles in Figure 2) define plant characteristics that directly determine the capture of available resources. The other variables not included in this model are deriving variables that characterize the effect of environmental conditions on the whole system.

The amount of resource acquired by a plant is determined by resource availability and the rate of resource uptake or resource capture efficiency (LCE, WCE and NCE for light, water and nutrient capture efficiency, respectively, in Figure 2). Plant biomass is considered a product of its cumulative total resource uptake and resource use efficiency (i.e. rate of biomass production per unit of resource acquired or LUE, WUE and NUE for light, water and nutrient use efficiencies, respectively, in Figure 2). Biomass is composed of carbon $(W)$ and nutrient content $(U)$, and the ratio $U / W$ gives a measure of nutrient concentration $(C)$. Carbon is allocated to different plant components (leaves, stem, fruits and roots) that determine the plant's physiological characteristics that further influence resource capture (Berendse and Elberse 1990). Greater proportional allocation to roots increases root density, hence improve efficiency or rate of capturing soil resources, while preferred allocation to shoots enhances growth rate because of higher leaf area index (LAI), thus photosynthesis. The loss rate $(L R)$ determines the rate of nutrient return to the soil as mulch or root decay. Application efficiency (NA) determines the rate by which added nutrients are made available for uptake.

Resource acquisition and use involve three major processes: nutrient uptake, moisture absorption, and photosynthesis. Moisture availability influences growth through photosynthesis because of its effect on plant water status and hence leaf conductance (Burdett 1990), and nutrient absorption since it is required for diffusion and absorption of nutrient ions (Gillespie 1989; Smesthurst and Comerford 1993). In ecosystems in which at least one resource is limiting, biomass production can be regarded as a function of the amount of limiting resource(s) and their utilization efficiency. Interspecific plant interactions occur when one species affects availability of one or more resources to the other species, or simply alters environmental conditions favorable for the flow of material between state variables. Competition will reduce availability and flow of resources, while synergism will increase resource availability to the neighboring species. The mechanisms associated with this model are discussed in the following section.

\subsection{Partitioning of soil nutrients}

The conceptual framework in Figure 2 shows that there is mutual interdependence between nutrient uptake, moisture absorption and photosynthesis (Kropff et al. 1984). For example, increased nutrient availability and uptake accelerates photosynthesis that, in turn, promotes uptake and use of nutrients, and vice versa. Competition for soil nutrients may also reduce nutrient content and leaf area, thus resulting in reduced photosynthesis and growth that, in part, has a negative effect on nutrient uptake. Also, competition for moisture reduces plant water status and leaf conductance (thus reduced photosynthesis and growth), and may impair nutrient uptake since moisture is required for nutrient absorption by the roots.

The question as to which of these resources is the primary (direct) and secondary (indirect) growth limiting factor in competitive situations often poses considerable difficulty in interpreting observed effects of competition (Nambiar and Sands 1993). For example, most 


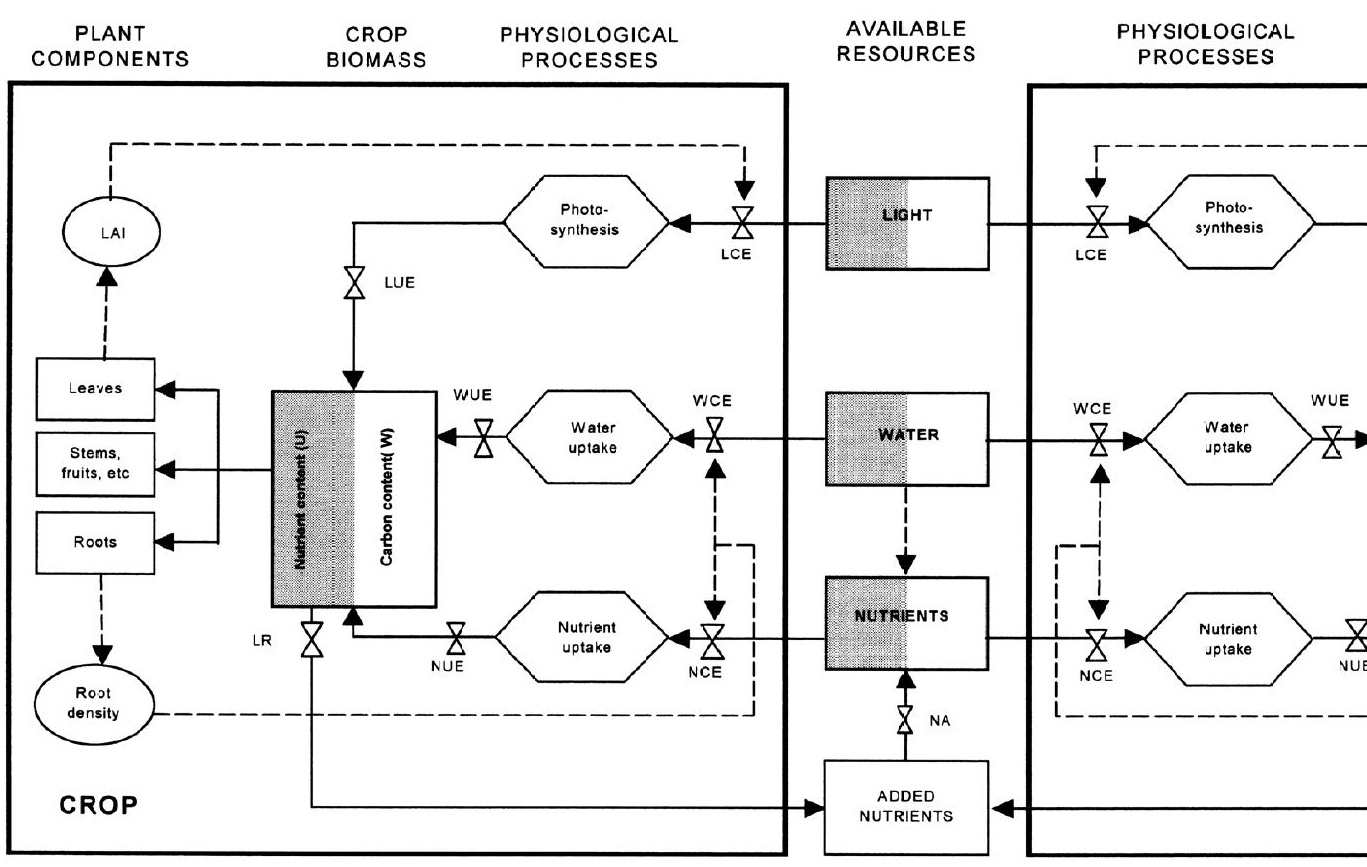

Fig. 2. Conceptual processes of resource competition between a crop and neighboring non-crop. Boxes represen rate variables; circles represent intermediate variables; and hexagons represent physiological processes. Solid a while broken arrows are flow of information or signals, and indicate occurrence of feed-back processes. Availal between competing plant species: shaded for the crop, and unshaded for the non-crop. LCE, WCE and NCE are efficiency, respectively. LUE, WUE and NUE are light-, water- and nutrient-use- efficiency, respectively. Bioma nutrients (U), and nutrients are returned to the soil as mulch as determined by the loss rate (LR). Nutrient appli the rate of conversion of added nutrients to available nutrients. Adapted from Imo (1999). and based on Kropf $e$ 
studies reporting on moisture competition hardly have measurements on tree nutrition even when treatments may have substantial impacts on soil nutrient availability and uptake (Coates et al. 1991). Hence, the relative significance of competition for moisture versus nutrients is usually ignored, especially in environments in which both moisture and nutrients are limiting. Unlike moisture, however, nutrients accumulate in plant biomass. Since moisture affects both photosynthesis and nutrient absorption, the approach in this chapter is to evaluate the effects of competition on carbon accumulation and nutrient content as shown in Figure 2. The fundamental question, therefore, is how competition affects carbon assimilation relative to nutrient uptake.

In Figure 2, carbon $(W)$ and nutrient content $(U)$ are assumed to be an integrated measure of availability, uptake and use of light, moisture and nutrients by plants, and are regulated by other environmental factors (i.e. deriving variables). When competition is primarily for soil nutrients, a reduction in $U$ will be large relative to a corresponding reduction in $W$, and $U / W$ (i.e. nutrient concentration) will also decline. When competition is primarily for light, then reduction in $U$ will be small relative to reduction in $W$, and $U / W$ will increase. When nutrients are non-limiting and competition is primarily for moisture, reduction in $U$ will also be small relative to reduction in $W$, and $U / W$ will increase.

In environments where both water and nutrients are limiting, moisture competition is expected to have overriding effects because water molecules are more mobile than nutrient ions in the soil, hence would have larger and greater overlapping depletion zones than nutrients (Gillespie 1989; Smesthurst and Comerford 1993). Thus, reduction in $U$ will be small relative to reduction in $W$, and $U / W$ will increase. Also, increased growth associated with (1) elevated nutrient levels (both concentration and uptake) reflects positive fertility effects, and (2) increased uptake but decreased nutrient concentration exemplifies improved moisture, light and or microclimate favorable for crop growth without significant effects on nutrient availability. These principles have been illustrated using interactions involving $\mathrm{N}$ responses in order to confirm these interpretations (Imo and Timmer, 1999a; 1999b). The treatments in these studies were selected to represent competition-free status and the other three interaction types (antagonistic, synergistic and compensatory). Although this technique may be applicable to all other nutrients when the same resources are removed, total resource availability to the other species should increase resulting in maximum growth and nutrient uptake potential (Imo 1999).

\subsection{Nutrient uptake and plant growth relationships}

Since nutrient concentration and content of a plant gives an integrated estimate of both total uptake and use by a plant (Imo 1999), studying the relationships between the two fundamental processes involved (i.e. nutrient accumulation and biomass production) can provide insight into the mechanisms involved. Chemical analysis of plants is frequently used to diagnose the nutritional status of plants since the plant itself is the object of interest, and its nutrient composition reflects many of the factors affecting its nutrition. Traditionally, plant nutrient composition is expressed either in relative term s (i.e. concentration $[C]$, the amount of nutrient present per unit amount of biomass) or on total mass basis (i.e. absolute content $[U]$, the total amount of nutrient present in a specific amount of plant tissue [W]). Total content is obtained by multiplying concentration by dry mass of the sample, thus $U=C(W)$. Imo and Timmer (1997) and Timmer (1991) have previously argued that using concentration alone does not 
reveal the mechanism on how nutrient content and dry mass are related, since changes in concentration may be caused by changes in either biomass or nutrient uptake or both, and there is no way of distinguishing between these mechanisms. Changes in concentration as a result of changes in content implies that the plant itself altered nutrient uptake and synthesis, while changes in concentration due to changes in biomass can be regarded as a growth response without any specific effects on metabolism of the nutrient.

\section{Measuring plant competition for nutrients}

\subsection{Root exclusion experiments}

Belowground competition is measured by quantifying the extent that root interactions reduce nutrient uptake and plant growth by preventing root interactions using root exclusion tubes, trenching, or neighbor removal to separate the roots of target individuals from those of neighboring plants. Root competition is determined by comparing the growth or survival of target plants inside the partitions with those having root systems that can interact freely with neighboring vegetation. Neighbors within partitions are killed by a fastdegrading herbicide, severed at the soil surface to remove shoots, or removed completely by excavating, sieving, and replacing the soil. Unfortunately, such methods often alter the soil environment and may even affect the availability of resources for which the plants are competing. To address this issue, many studies have proposed various competition indices to characterize the degree to which the growing space of a target crop is shared by weedy vegetation in agro-ecosystems and forest plantations by developing functional relationships between target crop or tree responses to some measure of non-crop (weed) proximity. Some of these indices are discussed below.

\subsection{Competition indices}

\subsubsection{Additive and substitutive indices}

The traditional approach has been to use competition indices to predict yield losses due to weeds in forestry and in agricultural systems (Morris and McDonald 1991; Wagner, 1994; 1993). Similarly, a competition index (i.e. tree-crop-interaction [TCI] equation) has been proposed to quantify the balance between competitive and beneficial effects of trees on crops in agroforestry systems (Ong 1996). Although these competition indices often demonstrate occurrence of likely competition, they fail to explain the specific processes and mechanisms involved, thus complicating interpretation of competition or beneficial effects between plants and making extrapolation of results to other situations difficult. Available mechanistic models usually focus on competition for a single resource. Physiological models of competition for light or moisture in agricultural ecosystems (e.g. Kropff 1993; Ong et al. 1996) and competition for nutrients in natural plant communities (e.g. Berendse et al. 1989) are examples of models based on single resources. However, plant growth involves acquisition, partitioning and interactions among multiple resources, making it difficult to determine if competition occurred for one or more resources. Understanding how growth resources are partitioned between neighboring species is, therefore, important in providing a scientific base for designing more productive cropping systems.

Various experimental methods have been used to elucidate competitive interactions in cropping systems, most of which have often considered only two-species mixtures as 
summarized by Radosevich (1988). The outcome of interspecific plant competition is influenced by factors of plant proximity such as density, spatial arrangement of plants, and the proportion of each species in mixtures. These methods rely mainly on using various regression models based on the growth-density relationship by assessing intercrop productivity in relation to performance in monoculture. To achieve this, three main methods used have been proposed to elucidate interspecific plant competition in agro-ecosystems, additive, substitutive and neighborhood experimentation. In additive experiments, two or more species are grown together with the density of one species held constant while that of the other species is varied. Hence, the additive approach is relevant to studying weed competition in agricultural systems where weeds often invade an area occupied by a fixed density of the crop and typically follows the 'law of diminishing returns' (Roadosevich 1988). Crop productivity diminishes with increasing weed density until weed density does not reduce crop productivity significantly. The main disadvantage of this approach is that both density and proportion of the species under study keep varying making it difficult to assess the relative effects of intraspecific and interspecific competition on total productivity. Some of these limitations have been addressed using the replacement series (or substitutive) experimental designs, whereby proportions of the two species vary in mixture, but total density remain constant. This approach is important where there are management interventions that are likely to have significantly different outcomes depending on which of these principles is in play under a specific set of conditions.

The yield of each species in mixture is expressed relative to their respective yields in monoculture. The sum of the relative yields is referred to as the relative yield total (RYT) or land equivalent ratio (LER), and have been used widely to assess the competitive ability of different species in mixture, and to evaluate the advantages associated with intercropping (Spitters 1983). If $R Y T>1.0$, then there is a true advantage of mixed cropping and indicates that the mixture as a total captures more resources than the respective monocultures, whereas competitive effects are indicated by $R Y T<1.0$. The main problem with this approach is that model coefficients vary with total density (Taylor and Aarssen 1989).

\subsubsection{Neighborhood competition indices}

To address these issues, Goldberg and Werner (1983) introduced a 'neighborhood' experimental approach, in which performance of a target individual is assessed as a function of the number, biomass or distance of its neighbors. The target species is either grown alone or is surrounded by individuals of the neighboring species. The relationship between target species and its neighbors is then expressed in terms of production of individual plants. This enables the determination of whether competition for resources is occurring since biomass is assumed to be proportional to total resource use by plants (Goldberg 1990). The basic argument is that comparing the slopes of the relationship between competing species provides a useful approach to studying competitive effects of neighboring species (Malik and Timmer 1996; Imo and Timmer 1997). Thus, lack of relationship indicates no interaction (neutral), and that resource use efficiency is constant with increasing neighbor biomass, while positive relationships would show synergistic interactions giving rise to over-yielding at increasing density. On the other hand, negative relationships indicate competition for resources resulting in lower yields with increasing density. 


\subsubsection{Limitations of competition indices}

However, it is difficult to determine from these regression models if competition occurred for one or more resources since competitive interactions involve partitioning of multiple resources (Nambiar and Sands 1993; Trenbath 1976). Berkowitz (1988) proposed a conceptual model of resource competition between a target plant and its neighbor that explicitly includes partitioning of the three main limiting resources (light, moisture and nutrients). In this model, competition may result from direct reduction in resource availability because of competitive uptake, or indirectly by reducing the uptake capacity of the other plant through resource-mediated alterations of the environment. These mechanisms are examined in the following section with respect to nutrient partitioning between competing plants, a major factor affecting species performance in plant communities (Berendse and Elberse 1990).

Despite general agreement that plant competition usually involves interactions between plants for different resources, most studies reporting competition fail to explain the processes and mechanisms involved (Nambiar and Sands 1993; Wilson and Tilman 1991), thus making it difficult to identify the resources which led to the interactions. According to Goldberg (1990), examining effects and responses of competing plants to resource availability can provide insight into the processes and mechanisms involved. This approach is adopted in this chapter, since both plant effects on resources and plant responses to resource availability can be quantified. As indicated earlier, the objective is to examine the concept of plant competition for nutrient resources, examine mechanisms partitioning of soil nutrients between neighboring plants, explain relationships between nutrient availability and plant growth, and to develop a theoretical basis for elucidating interspecific plant nutrient interactions. Although both light and moisture influence plant growth, the focus here is on interactions involving nutrients. However, attention is given to the role of moisture and light where these resources may directly influence nutrient availability, uptake and use by plants.

Unfortunately, these indices often focus on relating crop responses to some measure of weed proximity (Goldberg and Werner 1983; Radosevich 1988). Also, treatment impacts are often evaluated on the basis of survival, growth and yield of the target crops without considering non-crop responses, a major weakness for ecologically based assessments. Moreover, applications of these indices hardly explain the mechanisms involved. Little attention has also been given to determine whether competition is primarily for light, moisture and/or nutrients. The advantages and limitations of these indices are discussed in a review by Burton (1993) who advocated replacing static competition indices with a more site-specific phytometric approaches that feature greater accounting of neighboring noncrops and systematic local calibration and verification.

Distinguishing between these processes is important to test hypotheses related to the effect of changing nutrient supply on plant growth and nutrient composition. One way of solving this problem is by first studying the effects of nutrient supply on each of the individual plant response variables (i.e. biomass, nutrient concentration and content), and then examining their interrelationships using Vector Nutrient Analysis model (Timmer 1991; Imo and Timmer 1998). Traditionally applied to a single crop, this diagnostic format is unsuitable for interpreting competition effects in which growth resources are partitioned between interacting plants. Thus, the format has been modified by combining responses of 
competing plants to allow interpretation of interspecific interactions in a model called vector competition analysis (Imo and Timmer 1998). The focus, however, remains the same: identifying growth and nutritional interactions within the framework of vector diagnosis by characterizing the relationships between biomass production, nutrient accumulation and nutrient concentration of both species in mixture relative to their status in monoculture. These relationships are then synthesized into a diagnostic model (vector competition analysis) for elucidating interspecific plant growth and nutrient interactions.

In the following section, a graphical framework that helps discern interspecific competition effects involving nutrients and helps understanding probable mechanisms for nutrient competition in cropping systems is outlined. Functioning of the model is demonstrated using case studies from previous studies involving nutrient relationships in plants growing alone or in mixture, thus elucidating crop and weed nutrient interactions by examining the extent to which nutrients influenced the observed growth responses will be used to illustrate functioning of the model in screening impacts of different vegetation management regimes including use of herbicides, fertilization and nutrient loading as weed control measures in young forest plantations (Timmer 1997; Mead and Mansur, 1993), managing tree-crop interactions in alley cropping (Imo and Timmer 2000), and crop and tree interactions in taungya* systems of plantation establishment (Imo 2010).

\section{The vector competition analysis model}

The objective of this section is to provide the theoretical background of the model and to demonstrate its function in elucidating interspecific growth and nutrient interactions in plants. Although scientists have often studied competition to understand succession patterns, as well as growth, diversity and dynamics of plant communities, such studies have focused mainly on minimizing the effects of competing weeds by developing predictive tools for yield-loss assessment, and also to minimize the use of herbicides (Altieri and Liebman 1988). Also, much research has been conducted to maximize the output of intercropping systems (Willey 1979; Vandermeer 1989; 1998). In agricultural ecosystems, concepts such as 'vegetation management' or 'weed management' are important considerations in yield improvement, and often include a broad spectrum of concerns such as biodiversity, the effects of different management practices on competitive interactions, and sustainable crop production. The general view is that any vegetation or weed management should aim to suppress the non-crop only to the extent that it significantly interferes with the target crop. More recently, similar concepts have been extended to agroforestry where biophysical benefits and consequences of including trees in farm land management (e.g. competition for resources and improvement of soil fertility) are major factors in designing mixed cropping systems (Ong and Huxley 1996). The objective here is to minimize competitive effects between plants, while taking advantage of the beneficial effects of trees on the crop. According to Nambiar and Sands (1993), the difficulty with these concepts is defining levels of 'significant' interference, as well as establishing criteria for segregating competition effects.

\footnotetext{
*An agroforestry system involving planting tree seedlings in combination with food crops by first growing crops with tree seedlings for 3 - 4 years, after which trees are left to grow alone. This planting sequence eliminates weed competition, while tree and crop competition is minimized.
} 


\subsection{Model theory}

Vector competition analysis is modeled on regression analysis to evaluate competition effects (Goldberg and Werner 1983; Malik and Timmer 1995), and vector diagnosis is often used to assess plant nutrient status by identifying nutritional effects of nutrient dilution, deficiency, sufficiency and excess uptake (Haase and Rose 1995; Imo and Timmer 1997). The effect of non-crop weedy vegetation $(V)$ on the target crop $(T)$ is evaluated using the linear relationship $\left\{\left(T_{W}=Y_{W}+X\left(V_{W}\right)\right.\right.$ or $\left.T_{U}=Y_{U}+X\left(V_{U}\right)\right\}$, where $Y$ represents crop response in the absence of competition; $X$ is the slope of the regression; and $W$ and $U$ signify biomass and nutrient uptake, respectively. According to Goldberg and Werner (1983) and Goldberg (1990), the slope of the regression has a physical meaning: it provides a measure of competition intensity. The slope indicates no interactions when it is not significantly different from zero (0); indicates beneficial or facilitative effects of the vegetation if it is positive $(+)$; and indicates competitive effects of the vegetation if it is negative (-).

Malik and Timmer $(1995 ; 1996)$ have shown the effectiveness of this approach in describing relationships between growth of interacting black spruce (Picea mariana) seedlings and neighboring vegetation over a two-year period, which clearly demonstrated a significant negative relationship between seedling biomass and neighboring vegetation with seedling performance suffering at the expense of weed growth (Malik and Timmer 1996). Thus, reduction in weed biomass due to herbicide application resulted in reduced weed competition and a corresponding increase in biomass or nutrient content of the target crop. Since such a response often has both direction and magnitude, it can be characterized by a vector showing the combined crop and non-crop response (i.e. vector response).

Also, the slopes of such regressions serve as indicators of competition intensity (Goldberg 1990; Goldberg and Werner 1983), and may vary depending on site quality (Weldon et al. 1988). Management practices can also influence competition intensity as was demonstrated with herbicide application and nutrient loading (Malik and Timmer 1995; 1996). On the basis of these results, various possible impacts of weed management practices on the competitive interactions of crops and weeds, for example, herbicide application, may reduce weed competition in favor of the crop because of weed elimination. Fertilization may favor both the crop and weeds because of stimulated growth or may favor weeds more than the crop due to rapid weed growth resulting in shading of the crops; shading under the shelterwood system may reduce growth of both species. These varying treatment responses can be classified into four quadrants by two-dimensional graphical representation of the performance (biomass, nutrient content, yield or density) of one species (i.e. crop) plotted against that of the other species (e.g. weedy vegetation).

The principle is illustrated in Figure 3, which displays some possible combinations of the crop and non-crop (i.e. weedy vegetation): crop response plotted on the y-axis, and noncrop responses on the x-axis. First, performance of the crop in the absence of non-crop competition (when there is zero biomass of the non-crop) is plotted on the y-axis, while performance of the non-crop in the absence of the crop ( zero biomass of the crop) is plotted on the $x$-axis (Figure 3). The process of interspecific interaction can then be visualized as a change in these values along each axis when in mixtures. Competition will reduce performance of either species, while facilitation will increase species performance. Hence, performance of each species in mixture is represented by a point on the graph as summarized in Figure 3 depicting vectors of changing biomass production and nutrient 
uptake of interacting plants relative to competition-free status as described in the following section.

\subsection{Constructing vector competition diagrams}

In this model, biomass or nutrient content of the target crop is plotted on the y-axis against those of the neighboring non-crop vegetation on the x-axis (Figure 3). Although absolute data can be used in plotting vector competition diagrams, use of relative (normalized) values allows multiple comparisons among sites, treatments and nutrient elements by eliminating inherent differences in plant size and nutrient content (Timmer 1991). Normalization is achieved by dividing response parameters (biomass or nutrient content) for each treatment by corresponding values of the control or reference treatment, and expressed as percentage by multiplying by $100 \%$ to obtain relative biomass (W) and relative nutrient content $(U)$. The choice of the reference treatment depends on the specific objective of the analysis being conducted. For studies in which interspecific interactions is the focus, species performance without competition is used as the reference for comparison with its performance in mixture. Thus, effects of non-crops on the target crop are evaluated when performance of the sole crop is used as the reference (Figure 3). Similarly, effects of the crop on non-crops are assessed when performance of the non-crop in the absence of the target crop is the reference.

After normalizing the data, plotting starts with the reference treatments (i.e. sole crop $[y]=$ 100 , and sole non-crop $[x]=100$ ) as shown in Figure 3. This reference point represents the combined crop and non-crop response without competition. When plotting, it is important to have the same scale on both axes to form a square so as to avoid visual exaggerations. The second step is to plot crop and non-crop responses in mixture $(W$ or $U$ ) on the same diagram, each point representing the combined crop and non-crop mixture response to different treatments within one of the quadrants A, B, C or D (as shown in Figure3). The third step is to draw vectors from the reference point to the plotted data points to show the combined response in biomass or nutrient content of the crop as well as non-crop in mixture or due to specific treatments.

The final step is to draw a vertical and horizontal dashed line across the reference point to divide the vector competition diagram into four distinct quadrants (A, B, C and D) that help define interaction types (Box I in Fig. 3). Vector shifts below the horizontal dashed line indicate competitive effects of the non-crop since responses are negative, while shifts above indicate beneficial or facilitative effects of the non-crop because responses are positive. Similarly, vector shifts to the left of the vertical dashed line indicate competitive effects of the crop on the non-crop, while shifts to the right signify facilitative effects of the crop. Interpretations of these vector relationships are discussed below.

\subsection{Vector interpretations}

Diagnostic interpretation of the impacts of alternative management strategies on crops as well as non-crops is based on vector direction and magnitude observed as no change (0), increase (+), or decrease (-) relative to the reference status (Box I, Figure 3). Vector shifts in quadrant A indicate treatments that inhibit both species (antagonistic [-,-]); shifts in B show treatments that favor non-crop vegetation but not the target crop (compensatory $[-,+]$ ); shifts 
in C exemplify treatments that favor both species (synergistic $[+,+]$ ); and shifts in D illustrate treatments that favor the crop but not non-crop (compensatory $[+,-])$.

Slopes of the vectors define symmetry of the interactions. If crops and non-crops influence each other such that both species change by the same magnitude and in the same direction (as shown by vectors A, B, C and D in Figure 3), the slope will be one indicating symmetric interaction. Deviations from a slope of unity represent asymmetric interactions, and can be interpreted on the basis of vector orientation and magnitude within each of the four quadrants projected horizontally and vertically from the reference point (Figure 3). Vector deviations closer to the horizontal dashed line imply the non-crop is more sensitive to the treatments than the target crop, while those closer to the vertical dashed line indicate the crop is more sensitive to treatments. Similarly, a slope of zero indicates treatments that affect the non-crop without influencing the crop, while a slope of infinity exemplifies treatments that affect the crop without affecting non-crop.

\subsection{Diagnosis of plant growth and nutritional interactions}

Since nutrient concentration $(C)$ is a function of uptake $(U)$ and biomass $(W)$, thus $C=U / W$, interpretation of growth and nutritional interactions for each species can be determined based on the ratio between nutrient content vector $(U)$ and biomass vector $(W)$, thus $(U / W)$. This approach is adapted for several reasons: first, $W$ and $C$ can easily be determined using standard laboratory procedures, and $U$ is calculated for each sample by taking the product of concentration and dry mass, thus $U=C^{*} W$. Secondly, nutrient content (U) gives a direct measure of the amount of nutrients actually absorbed by the plant (Berkowitz 1988). Finally, the relationship $C=U / W$ enables one to determine whether changes in $C$ are associated primarily with changes in $U, \mathrm{~W}$ or both.

Diagnostic interpretations of these interactions are summarized in Box II, Figure 3. Nutrient dilution (or decline in concentration) occurs when $W>U$ (i.e. vector ratio $U / W<1$ ). Such dilution effect is antagonistic dilution if it is associated with reduced growth and nutrient uptake, or is growth dilution if it is associated with increased growth and nutrient uptake. Nutrient sufficiency occurs when $W=U$ (i.e. vector ratio $U / W=1$, Box II in Figure 3) indicating that rate of nutrient uptake matched growth increase or steady state nutrition (Ingestad and Lund, 1986; Imo and Timmer 1997). Nutrient accumulation occurs when $W<$ $U$ (i.e. vector ratio $U / W>1$, Box II in Figure 3) indicating that rate of nutrient uptake was higher than growth rate. Such accumulation is a deficiency response if it is associated with increase in both $W$ and $U$, but excess uptake if associated with decline in biomass and or nutrient uptake (Timmer 1991).

These interactions can also be determined graphically by plotting both biomass and nutrient uptake responses on the same vector competition diagram (illustrated later) as follows. For the crop component $(y)$, drawing a horizontal line (parallel to the $x$-axis) across the point indicating $W$ enables determination of the change in relative nutrient concentration depending on the relative position of the point indicating $U$. Nutrient dilution in the crop occurs when $U$ is below the horizontal line (i.e. $U<W$ ); nutrient sufficiency occurs when $U$ and $W$ lie on the same horizontal line (i.e. $U=W$ ); while nutrient accumulation occurs when $U$ is above the horizontal line (i.e. $U>W$ ). Similarly, changes in relative nutrient concentration for the non-crop $(x)$ can be determined by drawing a vertical line (parallel to the $y$-axis) across the point indicating $W$. Nutrient dilution in the non-crop occurs when $U$ is 
to the left (i.e. $U<W$ ), while accumulation occurs when $U$ is to the right (i.e. $W<U$ ) of the vertical line. Sufficiency occurs when $U$ and $W$ lie on the same vertical line (i.e. $W=U$ ).

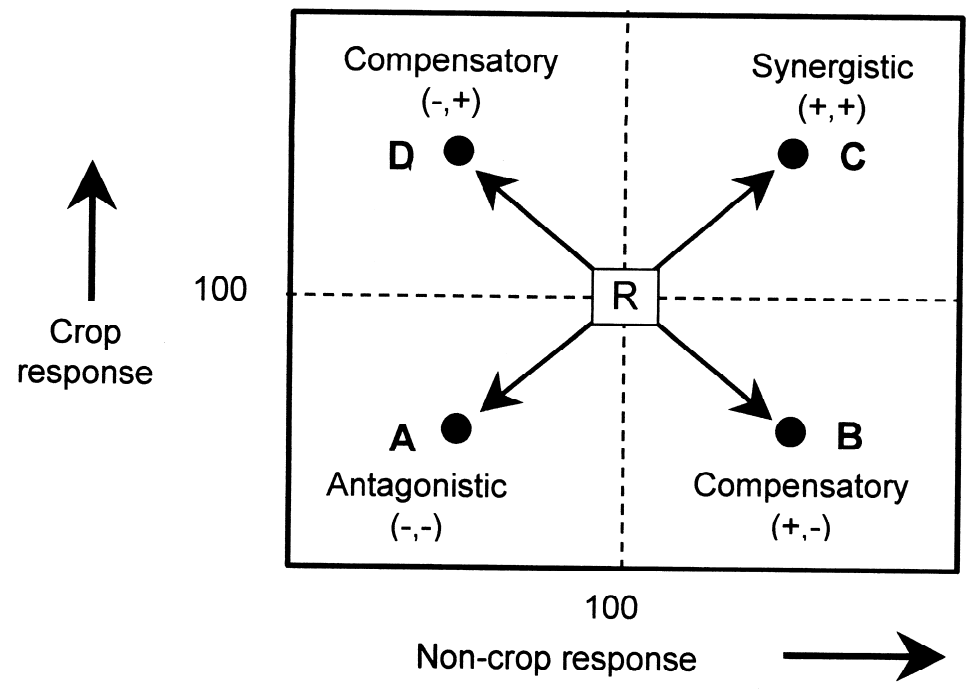

Box I: Competition responses

\begin{tabular}{|c|c|c|l|l|}
\hline \multirow{2}{*}{$\begin{array}{c}\text { Vector } \\
\text { shift }\end{array}$} & Relative response & & \\
\cline { 2 - 4 } & Crop & Non-crop & Interaction type & Likely management options \\
\hline A & - & - & Antagonistic & Weed control required; inter-cropping not feasible \\
B & - & + & Compensatory & Weed control required; not favoring inter-cropping \\
C & + & + & Synergistic & Weed control not required; inter-cropping feasible \\
D & + & - & Compensatory & Weed control not required; inter-cropping possible \\
\hline
\end{tabular}

Box II: Growth and nutritional interactions

\begin{tabular}{|c|c|c|c|c|}
\hline \multirow{2}{*}{$\begin{array}{l}\text { Vector } \\
\text { ratio } \\
(\mathrm{U} / \mathrm{W})\end{array}$} & \multicolumn{2}{|c|}{ Relative change in } & \multirow[b]{2}{*}{$\begin{array}{l}\text { Possible } \\
\text { diagnosis }\end{array}$} & \multirow[b]{2}{*}{ Possible interaction effects } \\
\hline & $\begin{array}{c}\text { Biomass } \\
\text { (W) }\end{array}$ & $\begin{array}{c}\text { Nutrient } \\
\text { content }(U)\end{array}$ & & \\
\hline $\begin{array}{l}<1 \\
<1 \\
=1 \\
>1 \\
>1\end{array}$ & $\begin{array}{l}- \\
+ \\
+ \\
- \\
+\end{array}$ & $\begin{array}{l}- \\
+ \\
+ \\
+ \\
+\end{array}$ & $\begin{array}{l}\text { Antagonistic dilution } \\
\text { Growth dilution } \\
\text { Sufficiency } \\
\text { Excess uptake } \\
\text { Deficiency }\end{array}$ & $\begin{array}{l}\text { Nutrient competition } \\
\text { Improved moisture and light availability } \\
\text { Improved nutrient, moisture and light availability } \\
\text { Light / moisture competition } \\
\text { Improved nutrient availability }\end{array}$ \\
\hline
\end{tabular}

Fig. 3. Graphical vector competition analysis model showing total nutrient use by neighboring tree crop and non-crop weedy species. Competition-free crop or non-crop weedy vegetation status is normalized to $100 \%$ as a reference $(R)$ for comparison with corresponding plants growing in mixture, respectively. The vertical and horizontal dashed lines divide the model into four quadrants (A, B, C and D) that characterize the type of interaction (Box I), while the associated growth and nutritional interactions are identified in terms of vector ratio in Box II. Adapted from Imo (1999); see also Imo and Timmer (2000; 2002). 
For a limiting nutrient, this interaction type is associated with a deficiency response (i.e. vector ratio $U / W>1$, Box II in Figure 3) since uptake is accelerated faster than growth in a manner similar to fertilization response. Synergistic nutrient interactions may also result from improved moisture availability, for example, mulching, reducing surface runoff and evaporation. This interaction may increase growth faster than nutrient uptake, thus resulting in growth dilution of nutrients (i.e. vector ratio $U / W<1$, Box II Figure 3) or sufficiency if both growth and nutrient uptake are increased at the same rate (i.e. vector ratio $U / W=1)$.

Competition for nutrients reduces growth and nutrient uptake of the species in mixture, and often occurs when nutrient availability is not sufficient to support the demand by either species, resulting in antagonistic competition (Shift A in Figure 3). This type of interaction results in antagonistic dilution of nutrients (i.e. $U / W<1$, Box II in Figure 3) indicating that competition reduced nutrient absorption more than photosynthesis. Interspecific nutrient interactions may also result in compensatory competition in favor of one species while the other is suppressed (Figure 3). For example, increasing nutrient availability through fertilization may favor growth of one species and cause preemption of other resources. Since nutrients are not limiting, this type of interaction results in excess nutrient uptake $(U / W>1$, Box II in Figure 3) indicating that photosynthesis was reduced more than nutrient absorption presumably because of light and or moisture preemption. The function of this model is demonstrated with response data from the following study.

It is important to note that this model has been developed primarily for screening alternative strategies of integrated vegetation management in forest plantations, cropping and agroforestry systems by evaluating crop and weed interactions in a bivariate graphical model depicting vectors of changing biomass production and nutrient uptake relative to competition-free status. Conceptually, this approach has the potential to contribute to efficient nutrient management in intensively managed cropping systems by providing a systematic framework for rationalizing management prescriptions as has been demonstrated for agroforestry systems in Western Kenya (Imo and Timmer (2001) and young forest plantations (Imo and Timmer 2000) where management of competing non-crop species is an important objective and the other where complementary use of growth resources by species in mixture is an important consideration in management decisions.

\section{Practical applications}

Since nutrient content is often used to give an integrated measure of total nutrient uptake and use by plants, determination of nutrient content of neighboring plants can provide insight into the processes of partitioning of soil nutrient resources between them (Berkowitz 1988). Although Imo and Timmer (1997) have previously diagnosed these nutritional effects using vector competition analysis without linkage to availability of other resources required for growth, it is well-known that plant growth depends on acquisition, retention and use of multiple resources (carbon, water, nutrients and light) as illustrated in Figure 2 (Trenbath 1976). Carbon and nutrients are converted into biomass, while light and water are necessary for growth and other physiological processes (Salisbury and Ross 1992), often involving complex interactions among various resources (Neary et al. 1990; Sands and Mulligan 1990; Woods et al. 1992). Plant growth characteristics may also influence resource interactions, for example, due to trade-offs in carbon allocation between resource acquiring organs or greater 
growth rate and overall plant size. Trade-offs between uptake organs predict a negative relation between competitive abilities for different resources, while accelerated growth and resource use predict a positive relation between competitive abilities for different resources (Tilman 1988). Unfortunately, most studies on plant competition often focus on effects of single resources without considering the processes involved (Nambiar and Sands 1993). This makes it difficult to determine whether interactions involved more than one resource. Figure 3 illustrates the impacts of management practices on resource partitioning between target crops and neighboring non-crop weedy vegetation as discussed below.

\subsection{Compensatory competition}

Compensatory competition occurs when growth of one species increases, while that of the other decreases (Shift B and C, Figure 3), and indicates re-allocation of available resources from one species for use by the other. This type of interaction occurred between natural vegetation and seedlings after fertilizer addition on the weed prone sites (Imo and Timmer 1999). Although fertilizer addition increased $\mathrm{N}$ availability to both species, growth and $\mathrm{N}$ uptake of neighboring non-crop vegetation were increased while those of seedlings declined. Nitrogen uptake and growth of the faster growing weeds were higher with carbon assimilates allocated primarily to aboveground, typical of plant responses to increased nutrient availability (Chapin 1987). With this allocation pattern, neighboring vegetation intercepted more light because of larger leaf area. Once these processes were established, a positive feedback mechanism between growth and resource capture (Grime 1979) presumably preempted available light and moisture from seedlings that in effect became suppressed. These responses confirm the hypothesis that competitive advantage of a species for one resource leads to an advantage for acquisition and use of the other resources as well (; Kropff et al. 1984).

Comparison of carbon $(W)$ and nitrogen $(U)$ accumulation in seedlings shows that both $W$ and $U$ were reduced, but proportional reduction in $W$ was larger than the corresponding reduction in $U$, hence $U / W$ increased signifying excess uptake of $\mathrm{N}$ (Box II in Figure 3). Thus, $\mathrm{N}$ was not limiting, and the suppressed seedling growth was probably because of preemption of available light and or moisture by the weeds. The proportionally lower $W$ than $U$ in weeds after fertilization indicates that $U / W$ also increased signifying a deficiency response (Box II in Figure 3).

\subsection{Antagonistic competition}

Antagonistic competition occurs when performance of both species in mixture is reduced (Shift A, Figure 3), probably because consumption by each species reduces resource availability to each other. This interaction type has been demonstrated in conventionally fertilized seedlings planted on high competition sites without any weed control treatment (Imo and Timmer 1998). In this study, growth and $\mathrm{N}$ uptake of both the seedlings and neighboring vegetation were reduced exemplifying mutual antagonism due to low $\mathrm{N}$ availability that was not sufficient to support growth demand of both the seedlings and competing vegetation, thus reducing uptake of both species. Reduction in weed biomass was, however, small compared to decline in seedling biomass (Imo and Timmer 1999) exemplifying asymmetric competition with the trees being more sensitive to competitive effects than the weeds. Further analysis of the results from this study indicated antagonistic 
dilution effects (Imo and Timmer 1997), suggesting that competitive interactions reduced nutrient uptake more than photosynthesis. It was therefore concluded that competition for $\mathrm{N}$ between the seedlings and the weedy vegetation was more important than for light and moisture. In contrast, nutrient loading, however, improved competitive ability of the seedlings, presumably because of a build-up of pre-plant $\mathrm{N}$ during the nursery phase.

\subsection{Synergistic interactions}

Synergistic interactions occur when performance of one or both species mixture is more than their performance when grown alone (Shift C in Figure 3), and indicates beneficial effects of one species on the other. This interaction type was demonstrated in an alley agroforestry system involving Leucaena trees inter-cropped with maize (Zea mays L.) in Western Kenya (Imo and Timmer 2000). In this study, maize crop productivity was significantly higher than the sole crop, which was attributed to higher $\mathrm{N}$ availability mineralized from added mulch. Apparently, the beneficial effects of the mulch for the crop were higher than the negative effects of competition by the Leucaena hedgerows for the other resources (i.e. available light and moisture). The frequent and rapid pruning regime applied ensured return of mulch to the soil hence maintaining high $\mathrm{N}$ availability to the crop while ensuring minimal effects of light competition by the hedgerow trees. It was also noted that, although both biomass and nutrient content of the crop increased, the increase in the latter was larger than a corresponding increase in the former, which resulted in a typical of deficiency response (Imo and Timmer 1997) due to improved fertility from mulching.

\subsection{Maximizing crop nutrient use}

In view of the factors influencing nutrient partitioning between competing plants discussed in the previous sections, crop productivity can be maintained or improved by tilting the balance in resource capture in favor of the target crops. Previous developments on integrated weed management in forestry and agriculture ), and tree and crop inter-cropping in agroforestry (Ong and Huxley 1996) have repeatedly emphasized the need to incorporate a combination of management approaches for different objectives. Given that such integrated methods for crop management are linked to biological, environmental and economic considerations (Nambiar and Sands 1993), the problem often encountered by many decision-makers is related to determining the level of significant interference of beneficial value of non-crop management interventions. The vector competition analysis approach presented in this thesis is a simple decision-support tool to reconcile these variable objectives, especially in relation to nutrient management. In this model, both crop and noncrop interaction types and the associated nutritional mechanism $s$ are evaluated in a systematic manner.

Figure 3 above has shown how this simple approach can be used to determine the partitioning of soil nutrients between neighboring plant species, and how efficiently the available nutrient resources are utilized on a site-specific and management specific-regime basis. Notice that the model emphasizes total nutrient use by the neighboring plant species according to the competitive production principle or facilitation discussed earlier. The lower-left portion (antagonistic interactions) in Figure 3 indicates competitive interactions between the species and demonstrates combinations in which total nutrient uptake and use by the two species in mixture is less than their total nutrient uptake and use when grown 
separately. This portion, therefore, represents inefficient exploitation of the site by the two species if planted as monocultures. The upper-right portion (synergistic interactions), on the other hand, shows complementary use of nutrients (or facilitation) between the neighboring species, and indicates that total nutrient uptake and use in by the plants in mixture is greater than their total uptake when grown separately, thus represents higher efficiency in resource capture and utilization. In practical terms, management practices that aim to suppress weed competition (as demonstrated in by Imo and Timmer 2001) operate within the lower-left portion, while inter-cropping practices such those in agroforestry (as demonstrated in Imo and Timmer 2000) aim at achieving species mixture within the upper-right portion of Figure 3. The main advantage of this approach is that it provides an instant evaluation of the advantage of intercropping or of specific management practices, and the possible processes involved.

In these studies, herbicide application on young black spruce plantations on high competition forest sites (Imo and Timmer 2001) eliminated weed competition, thus maximizing the amount of available resources to the target tree seedlings whose growth was increased. In theory, supplementing the resource pool of the crop by, for example, fertilization and irrigation should reduce competitive effects of the weeds. Results from this study, however, illustrated one major difficulty in this approach as was demonstrated by Imo and Timmer (2001) after fertilizing weed prone sites. Applied fertilizer was preferentially taken up by the weeds resulting in rapid weed growth and light preemption, consistent with the well established notion that weed resource use often increases more rapidly with added nutrients than that of the target crops.

In agroforestry, tree and crop inter-crops can be managed for spatial or temporal complementary use of nutrients to reduce competitive interactions while enhancing total nutrient use in the whole system (unshaded portion of Figure 3). Here, optimizing tree density and spacing is a key factor in complementary use of nutrients in these systems, and may be explained in terms of either the competitive production principle or facilitation (Vandermeer 1989). Several mechanisms may be associated with complementary use of nutrients in these systems such as nitrogen fixation since Leucaena is a N-fixing species (Kang et al. 1985), or the ability to access different nutrient pools or use of nutrients by the other species that would otherwise be lost to deep percolation.

These processes were confirmed from results with herbicide application on the high competition sites (Imo and Timmer 1999). Herbicides eliminated weed competition resulting in increased total resource availability to the seedlings. Light availability increased because of removal of aboveground weed biomass, while moisture and nitrogen availability increased presumably due to elimination of uptake by the weeds. Further, the dead weed material was returned to the soil as residue that mineralized to increase available $\mathrm{N}$ as was confirmed in the field. Vegetation removal presumably increased soil temperature as well and was favorable for rapid mineralization.

In the absence of weed competition, all available resources were utilized in seedling growth, thus the trees were able to achieve maximum carbon assimilation and nutrient uptake potential. Biomass production under this competition-free status was, therefore, maximized as supported by the significantly higher growth and nitrogen content of seedlings at the end of the growing season after herbicide application (Imo and Timmer 1999). Since both carbon 
$(W)$ and nitrogen $(U)$ content of the seedlings were maximized, seedling nutrient status can be considered sufficient for growth requirements under Compensatory competition

\section{Conclusions}

Several conclusions can be drawn regarding the effectiveness of the vector competition model to elucidate complex interspecific plant growth and nutrient interactions in cropping systems in a simplified graphical format. First, integrating processes of resource acquisition and use within a conceptual graphical framework provides an approach for obtaining insight into the mechanisms involved in nutrient partitioning between competing plants. Thus, appropriate management interventions can be designed to alter allocation of soil nutrients to favor targeted plant crops or to maximize total nutrient use by the competing species. This conceptual approach clearly illustrates the complex nature of resource acquisition, uptake and use by plants, yet the overall effects on growth and nutrient uptake can be elucidated in a very simplified manner using vector competition analysis. Also, these interactions vary over time, and are regulated by feedback processes within the plant itself and affected by many environmental conditions. The conceptual graphical framework may also provide a simplified framework for simulating individual processes of resource availability, uptake and use by the competing species, thus enabling the understanding of how these processes change under specific environmental conditions and management regimes.

Specifically, the model enabled identification of the nature of interspecific growth and nutritional interactions in plants competing for the same resources in terms of antagonistic, compensatory or synergistic interactions, as well as discern phenomena of symmetrical interactions by isolating the most responsive species and sites under different management regimes. By comparing biomass production, nutrient accumulation, and nutrient concentration of the competing species, vector competition analysis facilitated characterization of interspecific interactions involving nutrient competition, synergistic nutrient interactions, or non-nutrient competition responses. These interpretations were based on nutritional effects, namely: nutrient dilution, sufficiency or accumulation as summarized in Box II of Figure 3. Thus, the model is an improvement over traditional competition indices based only on morphological parameters. Since biomass and nutritional responses were normalized to a standard reference treatment $(100 \%)$, it was possible to compare treatments, sites and nutrient elements simultaneously. This standardization permitted ranking of weed problem sites, the model enabled identification of the nature of interspecific growth and nutritional interactions in plants competing for the same growth resources in terms of antagonistic, compensatory or synergistic interactions as shown in Box I of Figure 3.

The model further helped identify phenomena of symmetrical interactions by isolating the most effective vegetation management practices over a wide range of ecological conditions. Thus, the model can provide farm managers with a decision-support mechanism for identifying and ranking weed problem sites, and permits recommendations regarding silvicultural treatments for specific sites. Appropriate management practices that favor resource allocation to target crops or maximize total resource use can be designed to improve productivity of the whole cropping system. The vector competition analysis approach can then be used as a decision-support tool to evaluate and rank such practices in a systematic manner. 


\section{Future research directions}

As discussed earlier, weed or non-crop vegetation management in forestry and agriculture involves a wide range of complex issues: social, economic, ecological and their interactions. Thus, one of the most important concerns is associated with the use of different analytical criteria for the assessment of alternative crop and non-crop management alternatives. For example, assessments based entirely on yield (a biological criterion) can lead to completely different conclusions regarding desirability of alternative cropping systems than from an assessment based purely on cash value (an economic criterion). Thus, it is possible to recommend an ecologically viable cropping system that lacks economic feasibility, or vice versa. How can the different management criteria be integrated into a single vector competition model? This should allow prescription of appropriate management practices that are acceptable using both ecological and economic criteria.

Secondly, while the principles articulated in this chapter can be of general application over a wide range of interspecific plant growth and nutrient interactions, interpretations thus far are limited to only a two-species mixture, one growing season, and harvesting the total aboveground plant parts for analysis. Thus the question is whether the vector competition analysis approach can be extended to evaluate mutual or competitive effects of more than two species in mixture. An answer to this question is important especially in field studies under natural conditions where individuals of more than two species often affect each other. The other area is whether the vector competition model is able to evaluate interspecific competition responses over several seasons, thus enabling understand long-term dynamics in competition responses. The approach taken by Imo and Timmer (1997) with traditional vector nutrient diagnosis using Prosopis chilensis seedlings can provide a basis for modeling time-dependent competition responses in vector competition analysis.

The other issue is whether plant parts (rather than the total aboveground plant) can give an indication of competitive responses. This is an important question especially in forestry and agroforestry where monitoring competition effects will normally not involve harvesting the whole crop. Traditional methods usually applied to assess tree growth such as foliage biomass and chemistry, stem diameter or leaf area index can be useful indices if incorporated into vector competition analysis to assess competition responses. Some of these methods have been applied successfully with the traditional vector nutrient diagnosis (e.g. Imo and Timmer 2000).

Finally, the process model (Figure 2) integrating processes of acquisition, uptake and use of different resources raises a number of fundamental questions in terms of mechanisms involved in partitioning of nutrients between competing plants that need further investigation. For example: the critical 'competition-free' period during which all nutrient resources should be available for the target crops and the timing of management interventions should be investigated further to help design management interventions to maximize productivity of the target crop. Relating growth and nutritional interactions to environmental or plant variables that can be manipulated to provide further insight of limiting resources. For example, the relative effects of moisture availability on photosynthesis and nutrient uptake need to be quantified. There is a need to integrate vector competition analysis into detailed ecophysiological simulation models for the individual processes of resource availability, uptake and utilization by the competing species thus 
permitting understanding of how these processes change under specific environmental conditions and management regimes. Such understanding can help to predict the potential role of various environmental, plant attributes and management practices in determining the outcome of competitive interactions.

\section{Acknowledgment}

Funding support from the Moi University Annual Research Grant (ARG) is greatly acknowledged. I am also grateful to many colleagues who have helped review and proof read this manuscript.

\section{References}

Altieri, M . A. and Liebm an, M . (eds). 1988. Weed Management in Agroecosystem s: Ecological Approaches. CRC Press Inc., Boca Raton, Florida.

Axelsson, E. and Axelsson, B. 1986. Changes in carbon allocation patterns in spruce and pine trees following irrigation and fertilization. Tree Physiology, Vol. 2, pp 189-204.

Barber, S. A. 1984. Soil Nutrient Bioavailability: A M echanistic Approach. John Wiley and Sons, New York.

Begon, M ., Harper, J. L. and Townsend, C. R. 1996. Ecology, 3rd ed. Blackwell Sciences Ltd, London.

Berendse, F. and Elberse, W. Th. 1990. Competition and nutrient availability in heathland and grassland ecosystems. In Grace, J. B. and Tilman, D. (eds.). Perspectives on Plant Competition, Academic Press, New York. pp. 93-116. Berendse, F., Bobbink, R. and Rouwenhorst, G. 1989. A com parative study on nutrient cycling in wet heathlands ecosystem s. II. Litter decom position and nutrient $\mathrm{m}$ ineralization. Oecologia, Vol. 78, pp 338-348.

Berkowitz, A. R. 1988. Competition for resources in weed-crop mixtures. In Altieri, M . A. and Liebman, M . (eds.). Weed Management in Agroecosystems: Ecological Approaches. CRC Press Inc., Boca Raton, Florida. pp. 89-119.

Boot, R. G. B. and Mensik, M. 1990. Size and morphology of root system s of perennial grasses from contrasting habitats as affected by nitrogen supply. Plant and Soil, Vol. 129, pp 291-299.

Burdett, A. N. 1990. Physiological processes in plantation establishment and the development of specifications for forest planting stock. Canadian Journal of Forest Research. Vol. 20, pp 415-427.

Burton, P. J. 1993. Some limitations inherent to static indices of plant competition. Canadian Journal of Forest Research, Vol. 23, pp 2141-2552.

Chapin, F. S., III. 1990. The ecology and economics of storage in plants. Annual Review of Ecological Systems, Vol. 21, pp 423-447. Chapin, F. S., III. 1987. Adaptations and physiological responses of wild plants to nutrient stress. In Gabelm an, H.W. and Loughman, B.C. (eds.). Genetic Aspects of Plant Mineral Nutrition. Martinus Nijhoff, Boston. pp. 15-26.

Chapin, F. S., III. 1980. The $\mathrm{m}$ ineral nutrition of wild plants. Annual Review of Ecological Systems, Vol. 11, pp 233-260.

Coates, K. D., Emmingham, W. H., Radosevich, S. R. 1991. Conifer seedling success and microclimate at different levels of herb and shrub cover in a Rhododendron- 
Vaccinium-Menziensia com m unity of south central British Columbia. Canadian Journal of Forest Research, Vol. 21, pp 858-866.

Eastham, J. and Rose, C. W. 1990. Tree/pasture interactions in a range of tree densities in an agroforestry experiment. I: rooting patterns. Australian Journal of Agricultural Research, Vol. 41, pp 683-695.

Fowler N.L. 1986. The role of competition in plant communities in arid and semiarid regions. Annual Review of Ecological Systems, Vol. 17, pp 89-110

Gillespie, A. R. 1989. Modeling nutrient flux and interspecies root competition in agroforestry interplantings. Agroforestry Systems, Vol. 8, pp 257-265.

Goldberg, D. E. 1990. Components of resource competition in plant com m unities. In Grace, J. B. and Tilm an, D. (eds). Perspectives on Plant Competition, Academic Press, Inc. New York. 27-49 pp.

Goldberg, D. E. and P.A. Werner. 1983. Equivalence of com petitors in plant com m unities: A null hypothesis and a field experim ental approach. American Journal of Botany. Vol. 70, pp 1098-1104.

Grace, J. B. and Tilman, D. (eds). 1990. Perspectives on Plant Competition. Academic Press, Inc., New York.

Haase, D. L. and Rose, P. 1995. Vector analysis and its use for interpreting plant nutrient shifts in response to silvicultural treatments. Forest Science, Vol. 41, pp 54-66. Imo, M. 2010. Interactions amongst trees and crops in taungya systems of western Kenya. Agroforestry Systems, Vol. 76. pp 263 - 273. Online: ODI 10.1007/s104457-9164-z.

Imo, M. and Timmer, V.R. (2002) Growth and nutritional interactions of nutrient-loaded black spruce seedlings with neighboring natural vegetation under greenhouse conditions. Forest Science, Vol. 48, No. 1, pp 77-84.

Imo, M. and Timmer, V.R. (2000) Vector competition analysis of Leucaena-maize alley cropping system in western Kenya. Forest Ecology and Management, Vol. 126, pp 255 $-268$.

Imo, M. (1999). Vector competition analysis: a model for evaluating nutritional interactions in cropping systems. PhD thesis, University of Toronto, Canada. 164p.

Imo, M. and Timmer, V.R. (1999) Vector competition analysis of black spruce seedling responses to nutrient loading and vegetation control. Canadian Journal of Forest Research, Vol. 29, pp 474-486.

Imo, M. and Timmer, V. R. (1998). Vector competition analysis: a new approach for evaluating vegetation control methods in young black spruce plantation. Canadian Journal of Soil Science, Vol. 78, pp 3-15.

Imo, M . and Timmer, V. R. (1997). Vector diagnosis of nutrient dynamics in mesquite seedlings. Forest Science, Vol. 43. pp 268-273. Ingestad, T. and Lund, A. B. (1986). Theory and techniques for steady-state $\mathrm{m}$ ineral nutrition and growth of plants. Scandinavian Journal of. Forest. Research. Vol. 1, pp 439-453

Kang, B. T., Grim m e, H. and Lawson, T. 1985. Alley cropping sequentially cropped $m$ aize and cowpeas with Leucaena on a sandy soil in Southern Nigeria. Plant and Soil. Vol. 85, pp 267-277.

Kropff, M . J. (1993). Eco-physiological models for crop-weed competition. In Kropff, M . J. and van Laar, H. H. (ed.). Modeling Crop-Weed Interactions, CAB International, Wallingford, UK. pp. 25-31.

Kropff, M . J., Vossen, F. J. H., Spitters C. J. T. and de Groot, W. (1984). Competition between a maize crop and a natural population of Echinochloa crus-galli (L.). Netherlands Journal of Agricultural Sciences, Vol, 32, pp 324-327. 
Malik, V. and Timmer, V. R. (1998). Biomass partitioning and nitrogen retranslocation in black spruce seedlings on competitive mixedwood sites: a bioassay study. Canadian Journal of Forest Research, Vol. 28, pp 206-215.

Malik, V. and Timmer, V. R. (1996). Growth, nutrient dynamics, and interspecific competition of nutrient-loaded black spruce seedlings on a boreal mixedwood site. Canadian Journal of Forest Research, Vol. 26, pp 1651-1659.

Malik, V. and Timmer, V. R. (1995). Interaction of nutrient-loaded black spruce seedlings with neighboring vegetation in greenhouse environments. Canadian Journal of Forest Research, Vol. 25, pp 1017-1023.

Marschner H. (1995). Mineral Nutrition of Higher Plants. London: Academic. 2nd ed.

Mead, D. J. and Mansur, I. (1993). Vector analysis of foliage data to study competition for nutrient and moisture: an agroforestry example. New Zealand Journal of Forest Science, Vol. 23, No. 1, pp 27-39.

Morris, D. M . and McDonald, G. B. (1991). Development of a competition index for young conifer plantations established on boreal mixedwood sites. Forestry Chronicle, Vol. 63, pp 1696-1703.

Nambiar, E. K. S. (1990). Interplay between nutrients, water, root growth and productivity in young plantations. Forest Ecology and Management, Vol. 30, pp 213-232.

Nambiar, E. K. S. and Fife, D. N. (1991). Nutrient retranslocation in temperate conifers. Tree Physiology, Vol. 9, pp 185-207.

Nambiar, E. K. S. and Sands, R. (1993). Competition for water and nutrients in forests. Canadian Journal of Forest Research, Vol. 23, pp 1955-1968.

Neary, D. G., Rockwood, D. L., Comerford, N. B., Swindel, B. F. and Cooksey, T. E. (1990). Importance of weed control, fertilization, irrigation and genetics in slash and loblolly pine early growth on poorly-drained Spodosols. Forest Ecology and Management, Vol. 30, pp 271-281.

Nye, P. H. and Tinker, P. B. 1977. Solute movement in the soil-root system. Blackwell, Oxford.

Ong, C. K. 1996. A framework for quantifying the various effects of tree-crop interactions. In Ong, C. K. and Huxley, P. (eds.). Tree-Crop Interactions: A Physiological Approach, CAB International, UK. pp. 1-23.

Ong, C. K. and Huxley, P. (eds.). (1996). Tree-Crop Interactions: A Physiological Approach. CAB International, Wellington, UK.

Ong, C. K., Black C. R., Marshall F. M . and Corlett J.E. (1996). Principles of resource capture and utilization of light and water. In Ong, C. K. and Huxley, P. (eds.). Tree-Crop Interactions: A Physiological Approach. CAB International, Wallingford, UK. pp. 73158. Radosevich, S. R. 1988. Methods to study crop and weed interactions. In Altieri, M. A. and Liebm an, M. (eds.), Weed Management in Agro-Ecosystems: Ecological Approaches. CRC. Press Inc., Boca Raton, Florida. pp. 121-143.

Salisbury, F. B., and Ross, C. W. 1992. Plant Physiology. Wadsworth Publishing Company, Belmont, Carlifornia, USA.

Sands, R. and Mulligan, D. R. (1990). Water and nutrient dynamics and tree growth. Forest Ecololgy and Management, Vol. 30, pp 91-111

Smesthurst, P. J. and Comerford, N. B. (1993). Simulating nutrient uptake by using single or competing root systems. Soil Science Society of America Journal, Vol. 57, pp 1361-1367.

Smesthurst, P. J. and Nambiar, E. K. S. (1989). Role of weeds in the management of nitrogen in a young Pinus radiata plantation. New Forest, Vol. 3, pp 203-224. Spitters, C. J. T. 1983. An alternative approach to the analysis of mixed cropping experiments. 1. 
Estimation of competition effects. Netherlands Journal of Agricultural.Sciences. Vol. 31, pp $1-11$.

Stone, E. L. and Kalisz, P. J. (1991). On the maximum extent of tree roots. Forest Ecology and Management, Vol. 46, pp 59 - 102.

Taylor, D. R. and Aarssen, L. W. (1989). On the density dependence of replacement-series competition experiments. Journal of Ecology, Vol. 77, pp 975-988.

Tilman, D. (1988). Plant Strategies and the Dynamics and Structure of Plant Com munities. Monographs in Population Biology 20, Princeton University Press, Princeton, New Jersey.

Timmer, V. R. (1997). Exponential nutrient loading: a new fertilization technique to improve seedling performance on competitive sites. New Forest, Vol. 13, pp 279-299.

Timmer, V. R. (1991). Interpretation of seedling analysis and visual symptoms. In van den Driessche, R. (ed.). Mineral Nutrition of Conifer Seedlings. CRC Press, Boca Raton. pp. 113-134. Trenbath, B. R. 1976. Plant interactions in mixed crop communities. In Stelly, M . (ed.). Multiple Cropping. American Society of Agronomy, Special Publication No. 27. pp. 129-169.

van den Driessche, R. (1991). Effects of nutrients on stock performance in the forest. In van den Driessche, R. (ed.). Mineral Nutrition of Conifer Seedlings. CRS Press, Boca Raton, Boston.

Vandermeer, J. H. (1998). Maximizing crop yield in alley crops. Agroforestry Systems, Vol. 40, pp 199-206.

Vandermeer, J. H. (1989). The Ecology of Intercopping. Cambridge University Press, Melbourne.

Vandermeer, J. H. (1984). Plant competition and the yield-density relation. Journal of Theoretical Biology, Vol. 109, pp 393-399.

Wagner, R. G. (1993). Research directions to advance vegetation management in North America. Canadian Journal of Forest Research, Vol. 23, pp 2317-2327.

Wagner, R. G. (1994). Toward integrated forest vegetation management. Journal of Forestry, Vol 92, pp 26-30.

Wagner, R. G. and Radosevich, S. R. (1991). Neighborhood predictors of interspecific competition in young Douglas-fir plantations. Canadian Journal of Forest Research, Vol. 21, pp 821-828.

Wang, D., Bormann, F. H., Lugo, A. E. and Bowden, R. D. (1991). Comparison of nutrient use efficiency and biomass production in five tropical tree taxa. Forest Ecology and Management, Vol. 46, pp 1-21. Weldon, C. W., Slauson, W. L. and Ward, R. T. $(1988)$. Competition and abiotic stress shrubs in northwest Colorado. Ecology Vol. 69, pp 1566-1577.

Willey, R. W. (1979). Intercropping - its importance and its research needs. Part I. Competition and yield advantages. Field Crop Abstracts, Vol. 32, pp 73-85.

Wilson, J.B. (1988). Shoot competition and root competition. Journal of Applied Ecology, Vol. 25, pp 279-96

Wilson, S. D. and Tilman, D. (1991). Components of plant competition along an experimental gradient of nitrogen availability. Ecology, Vol. 73, pp 1050-1065.

Woods, P. V., Nambiar, E. K. S. and Smethurst, P. J. (1992). Effect of annual weeds on water and nitrogen availability to Pinus radiata trees in a young plantation. Forest Ecology and Management, Vol. 48, pp 145-163. 


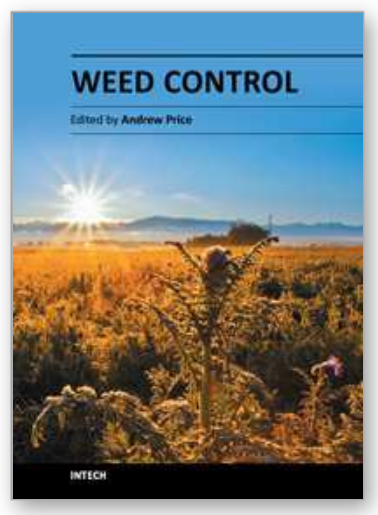

\author{
Weed Control \\ Edited by Dr. Andrew Price
}

ISBN 978-953-51-0159-8

Hard cover, 276 pages

Publisher InTech

Published online 29, February, 2012

Published in print edition February, 2012

Crop loss due to weeds has challenged agricultural managers since man began to develop the first farming systems. In the past century, however, much progress has been made to reduce weed interference in crop settings through effective yet mostly non-sustainable weed control strategies. With the commercial introduction of herbicides during the mid-1900's, advancements in chemical weed control tactics have provided efficient suppression of a broad range of weed species for most agricultural practices. Currently, with the necessity to design effective sustainable weed management systems, research has been pushing new frontiers on investigating integrated weed management options including chemical, mechanical as well as cultural practices. Author contributions to Weed Science present significant topics of research that examine a number of options that can be utilized to develop successful and sustainable weed management systems for many areas of crop production

\title{
How to reference
}

In order to correctly reference this scholarly work, feel free to copy and paste the following:

Moses Imo (2012). Managing Competition for Nutrients in Agro-Ecosystems, Weed Control, Dr. Andrew Price (Ed.), ISBN: 978-953-51-0159-8, InTech, Available from: http://www.intechopen.com/books/weedcontrol/managing-nutrient-competition-in-agro-ecosystems

\section{INTECH}

open science | open minds

\author{
InTech Europe \\ University Campus STeP Ri \\ Slavka Krautzeka 83/A \\ 51000 Rijeka, Croatia \\ Phone: +385 (51) 770447 \\ Fax: +385 (51) 686166 \\ www.intechopen.com
}

\author{
InTech China \\ Unit 405, Office Block, Hotel Equatorial Shanghai \\ No.65, Yan An Road (West), Shanghai, 200040, China \\ 中国上海市延安西路65号上海国际贵都大饭店办公楼 405 单元 \\ Phone: +86-21-62489820 \\ Fax: +86-21-62489821
}


(C) 2012 The Author(s). Licensee IntechOpen. This is an open access article distributed under the terms of the Creative Commons Attribution 3.0 License, which permits unrestricted use, distribution, and reproduction in any medium, provided the original work is properly cited. 